\title{
Relatively small earthquakes of Javakheti Highland as the precursors of large earthquakes occuring in the Caucasus
}

\author{
M. Kachakhidze ${ }^{1}$, N. Kachakhidze ${ }^{1}$, R. Kiladze ${ }^{2}$, V. Kukhianidze ${ }^{2}$, and G. Ramishvili ${ }^{2}$ \\ ${ }^{1}$ Tbilisi State University, Chavchavadze st. 2, Tbilisi 380028, Georgia \\ ${ }^{2}$ Abastumani Astrophysical Observatory, Kazbegi av. 2a, Tbilisi 380060, Georgia
}

Received: 21 June 2002 - Revised: 16 August 2002 - Accepted: 19 August 2002

\begin{abstract}
Javakheti Highland is one of the most seismic active regions of the Caucasus. The majority of earthquakes observed throughout the region occur within this small area $\left(\phi=40.8^{\circ}-41.8^{\circ} ; \lambda=43.3^{\circ}-44.3^{\circ}\right)$. One can expect that exclusive seismic activity of Javakheti Highland testifies to global geophysical processes which take place throughout the Caucasus region. Based on the above-mentioned, of interest was to study variation with time of the number of earthquakes occurring in Javakheti region. We analysed some 695 relatively small earthquakes $(2.5 \leq M<6.0)$ observed in Javalkheti Highland within the period of 19611992 with regard to large earthquakes $M \geq 6.0$ of the region which occurred in the same period. It was found that each large earthquake of the Caucasus is anticipated by clear precursor in a form of an anomalous change in the number of relatively small earthquakes in Javakheti Highland.
\end{abstract}

\section{Introduction}

From geological and geomorphologic viewpoints Javakheti Highland is one of the complex regions of the southern Georgia. It lies in the northern peripheral zone of the Transcaucasus-Asia Minor volcanic area, and to certain extent comprises territories of Armenia and Turkey as well.

Javakheti Highland is of special interest due to its highest seismic activity throughout the Caucasus: $55 \%$ of all Caucasian earthquakes occur there (Duff et al., 1980; KeilisBorok et al., 1980; Gotsadze et al., 1987; Kumaz et al., 1987; Chadwick et al., 1988, Kuloshvili et al., 1989; Handbook, 1990; Dea et al., 1991; Shebalin et al., 1999; Papadopoulos et al., 2000; Rundle et al., 2000; Sorrells et al., 2002; Westaway, 2002). Consequently, seismic activity of Javakheti Highland is the most obvious and it may reflect general changes in tectonic stress of the Caucasus region (Borisov et al., 1989; Park et al., 1993; Hayakawa et al., 2000; Tzanis et al, 2000).

Correspondence to: M. Kachakhidze

(manana_k@hotmail.com or manana_k@mail.ge)
Therefore Javakheti Highland may be "sensitive" to the large earthquakes.

The goal of our research was to study time-variation of the number of relatively small earthquakes occurring in Javakheti region with regard to large earthquakes of the Caucasus.

\section{Data}

Taking into consideration general pattern of earthquake distribution throughout the southern Caucasus, we decided to use comparatively broadened approach to Javakheti Highland, namely the territory defined by the coordinates was selected.

We have used an Earthquake Catalogue of the Caucasus region compiled by the Department of the Regional Seismology at the Institute of Geophysics, Georgian Academy of Sciences. The catalogue comprises all earthquakes with magnitude $M \geq 2.5$ observed in 1900-1992. After preliminary studies we had to restrict our analysis to the events occurred since 1961 - data on 1900-1960 earthquakes of Javakheti Highland seemed incomplete, as only 123 events were observed.

695 earthquakes of magnitude $(2.5 \leq M<6.0)$ occurred in Javakheti Highland within the time interval between 19611992. There were 16 large earthquakes in the whole Caucasus region with $M \geq 6.0$ including Spitak earthquake occurred on 7 December 1988 (epicentre of this earthquake was located in Javakheti Highland).

Data on the above large earthquakes are given in the Table 1. Figure 1 illustrates a map where the territory of Javakheti Highland under consideration is framed by quadrangle.

\section{Discussion}

Table 2, which shows monthly number of earthquakes observed during 1961-1992, was compiled to establish the rule of variation of the number of relatively small earthquakes of 


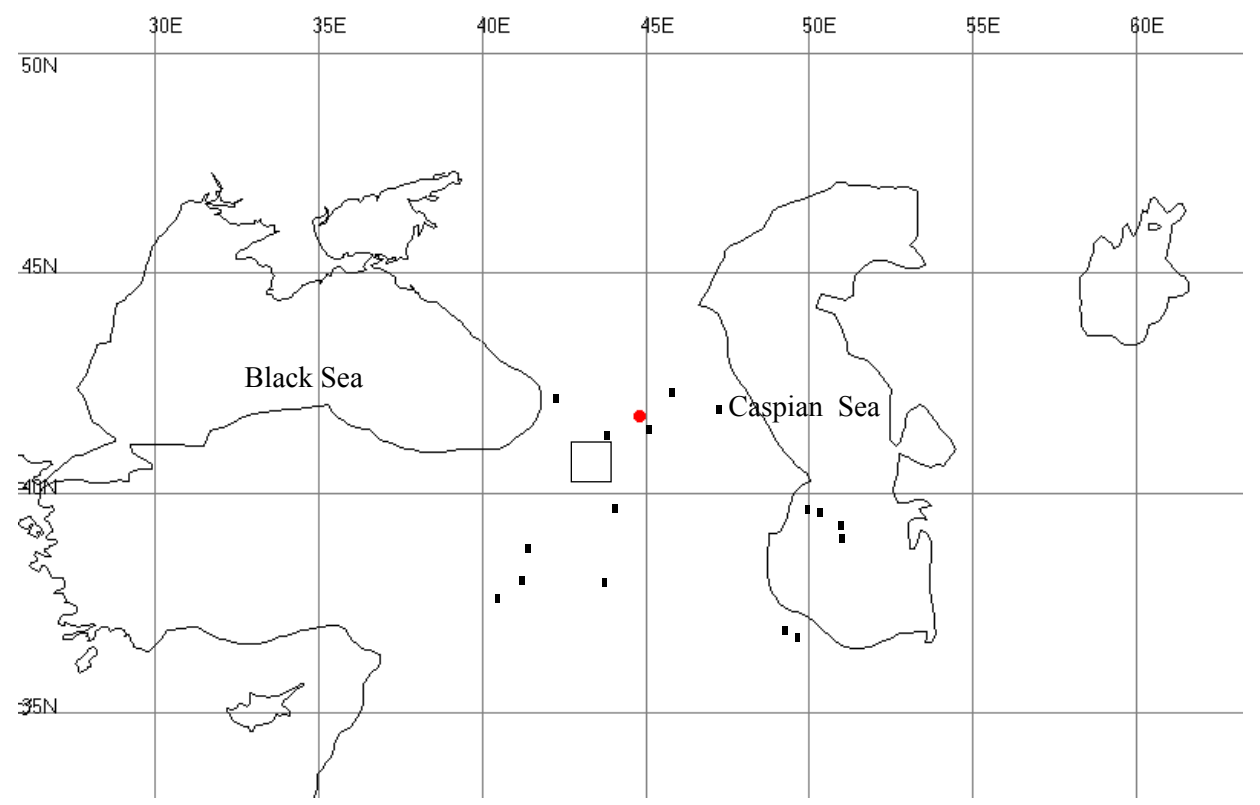

Fig. 1. Distribution of large earthquakes of the Caucasus.

Table 1. The data of large earthquakes of the Caucasus

\begin{tabular}{cccc}
\hline date & $\varphi$ & $\lambda$ & $\mathrm{M}$ \\
\hline 18 Sept. 1961 & $41.066 \mathrm{~N}$ & $50.233 \mathrm{E}$ & 6.6 \\
27 Jan. 1963 & $41.080 \mathrm{~N}$ & $49.840 \mathrm{E}$ & 6.2 \\
16 July 1963 & $43.180 \mathrm{~N}$ & $41.650 \mathrm{E}$ & 6.4 \\
19 Aug. 1966 & $39.166 \mathrm{~N}$ & $41.550 \mathrm{E}$ & 6.8 \\
14 May 1970 & $43.000 \mathrm{~N}$ & $47.083 \mathrm{E}$ & 6.6 \\
22 May 1971 & $38.850 \mathrm{~N}$ & $40.516 \mathrm{E}$ & 6.8 \\
28 July 1976 & $43.170 \mathrm{~N}$ & $45.600 \mathrm{E}$ & 6.2 \\
24 Nov. 1976 & $39.100 \mathrm{~N}$ & $44.000 \mathrm{E}$ & 7.0 \\
4 Nov. 1978 & $37.610 \mathrm{~N}$ & $49.040 \mathrm{E}$ & 6.0 \\
4 May 1980 & $37.800 \mathrm{~N}$ & $49.100 \mathrm{E}$ & 6.2 \\
30 Oct. 1983 & $39.983 \mathrm{~N}$ & $41.600 \mathrm{E}$ & 6.8 \\
6 March 1986 & $40.060 \mathrm{~N}$ & $51.630 \mathrm{E}$ & 6.1 \\
7 Dec. 1988 & $40.900 \mathrm{~N}$ & $44.200 \mathrm{E}$ & 6.9 \\
16 Sept. 1989 & $40.340 \mathrm{~N}$ & $51.600 \mathrm{E}$ & 6.3 \\
29 April 1991 & $42.390 \mathrm{~N}$ & $43.680 \mathrm{E}$ & 6.9 \\
23 Oct. 1992 & $42.490 \mathrm{~N}$ & $44.990 \mathrm{E}$ & 6.3 \\
\hline
\end{tabular}

Javakheti Highland. The corresponding graph (Fig. 2) was drawn on the base of the data given in Table 2 (here and elsewhere dark triangles stand for the occurrence of large earthquakes throughout the Caucasus within the same period).

Variation of the number of relatively small earthquakes of Javakheti Highland with time is shown in Fig. 2. We used the method of the Creeping Mean for better separation of the anomalies. Namely, we smoothed data series, from 2 to 20 months in length, with a lag of one month until the sharp picture was observed. The 9-month series were found the most appropriate for smoothing, since they proved to be acceptable for further processing and analysing (Comparatively worse graphs were obtained in case of smoothing time series

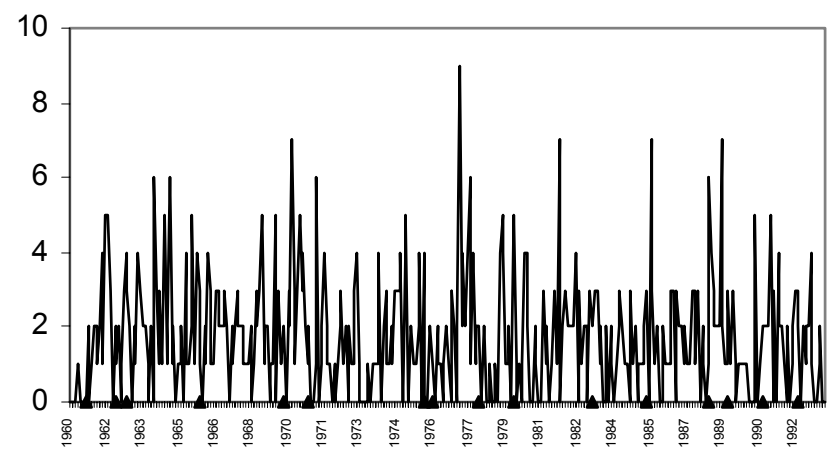

Fig. 2. Variation of the number of relatively small earthquakes with time.

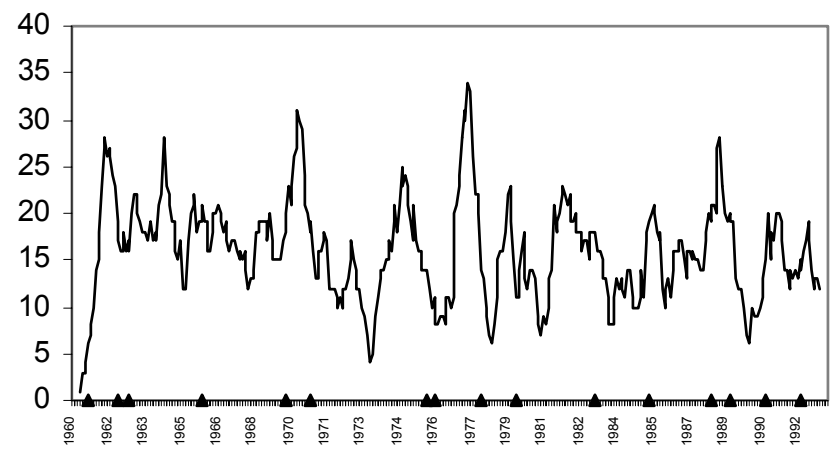

Fig. 3. A result of smoothing of the 9-month series of earthquakes distribution.

from 7 to 12 months in length. The series shorter or longer than that give distributions which are vague for interpreting) 9-month series choice has not any physical reason. It was chosen empirically because of being the best sygnal/noise 
Table 2. List of relatively small earthquakes of Javakheti highland

\begin{tabular}{|c|c|c|c|c|c|c|c|c|c|c|c|}
\hline year & month & quantity & year & month & quantity & year & month & quantity & year & month & quantity \\
\hline 1961 & 1 & 0 & 1965 & 2 & 5 & 1969 & 3 & 2 & 1973 & 4 & 1 \\
\hline 1961 & 2 & 0 & 1965 & 5 & 6 & 1969 & 8 & 2 & 1973 & 11 & 0 \\
\hline 1961 & 3 & 0 & 1965 & 6 & 1 & 1969 & 9 & 0 & 1973 & 12 & 0 \\
\hline 1961 & 4 & 0 & 1965 & 5 & 6 & 1969 & 6 & 1 & 1973 & 7 & 4 \\
\hline 1961 & 5 & 1 & 1965 & 6 & 1 & 1969 & 7 & 2 & 1973 & 8 & 1 \\
\hline 1961 & 6 & 0 & 1965 & 7 & 2 & 1969 & 8 & 2 & 1973 & 9 & 0 \\
\hline 1961 & 7 & 0 & 1965 & 8 & 0 & 1969 & 9 & 0 & 1973 & 10 & 0 \\
\hline 1961 & 8 & 0 & 1965 & 9 & 1 & 1969 & 10 & 1 & 1973 & 11 & 0 \\
\hline 1961 & 9 & 0 & 1965 & 10 & 1 & 1969 & 11 & 1 & 1973 & 12 & 0 \\
\hline 1961 & 10 & 2 & 1965 & 11 & 2 & 1969 & 12 & 5 & 1974 & 1 & 1 \\
\hline 1961 & 11 & 0 & 1965 & 12 & 0 & 1970 & 1 & 0 & 1974 & 2 & 0 \\
\hline 1961 & 12 & 1 & 1966 & 1 & 4 & 1970 & 2 & 3 & 1974 & 3 & 1 \\
\hline 1962 & 1 & 2 & 1966 & 2 & 1 & 1970 & 3 & 1 & 1974 & 4 & 1 \\
\hline 1962 & 2 & 2 & 1966 & 3 & 1 & 1970 & 4 & 2 & 1974 & 5 & 1 \\
\hline 1962 & 3 & 1 & 1966 & 4 & 2 & 1970 & 5 & 2 & 1974 & 6 & 1 \\
\hline 1962 & 4 & 2 & 1966 & 5 & 5 & 1970 & 6 & 0 & 1974 & 7 & 4 \\
\hline 1962 & 5 & 4 & 1966 & 6 & 1 & 1970 & 7 & 3 & 1974 & 8 & 0 \\
\hline 1962 & 6 & 1 & 1966 & 7 & 4 & 1970 & 8 & 2 & 1974 & 9 & 2 \\
\hline 1962 & 7 & 5 & 1966 & 8 & 3 & 1970 & 9 & 7 & 1974 & 10 & 3 \\
\hline 1962 & 82 & 5 & 1966 & 9 & 1 & 1970 & 10 & 3 & 1974 & 11 & 1 \\
\hline 1962 & 9 & 5 & 1966 & 10 & 0 & 1970 & 11 & 1 & 1974 & 12 & 1 \\
\hline 1962 & 10 & 3 & 1966 & 11 & 2 & 1970 & 12 & 3 & 1975 & 1 & 2 \\
\hline 1962 & 11 & 0 & 1966 & 12 & 1 & 1970 & 1 & 5 & 1975 & 2 & 1 \\
\hline 1962 & 12 & 2 & 1967 & 1 & 4 & 1971 & 2 & 3 & 1975 & 3 & 3 \\
\hline 1963 & 1 & 1 & 1967 & 2 & 3 & 1971 & 3 & 4 & 1975 & 4 & 3 \\
\hline 1963 & 2 & 2 & 1967 & 3 & 1 & 1971 & 4 & 2 & 1975 & 5 & 3 \\
\hline 1963 & 3 & 0 & 1967 & 4 & 1 & 1971 & 5 & 1 & 1975 & 6 & 4 \\
\hline 1963 & 4 & 1 & 1967 & 5 & 3 & 1971 & 6 & 2 & 1975 & 7 & 0 \\
\hline 1963 & 5 & 3 & 1967 & 6 & 3 & 1971 & 7 & 0 & 1975 & 8 & 4 \\
\hline 1963 & 6 & 4 & 1967 & 7 & 2 & 1971 & 8 & 0 & 1975 & 9 & 5 \\
\hline 1963 & 7 & 3 & 1967 & 8 & 2 & 1971 & 9 & 1 & 1975 & 10 & 0 \\
\hline 1963 & 8 & 2 & 1967 & 9 & 2 & 1971 & 10 & 6 & 1975 & 11 & 2 \\
\hline 1963 & 9 & 0 & 1967 & 10 & 3 & 1971 & 11 & 0 & 1975 & 12 & 2 \\
\hline 1963 & 10 & 2 & 1967 & 11 & 2 & 1972 & 12 & 1 & 1976 & 1 & 1 \\
\hline 1963 & 11 & 1 & 1967 & 12 & 0 & 1972 & 1 & 2 & 1976 & 2 & 1 \\
\hline 1963 & 12 & 4 & 1968 & 1 & 2 & 1972 & 2 & 4 & 1976 & 3 & 2 \\
\hline 1964 & 1 & 3 & 1968 & 2 & 1 & 1972 & 3 & 2 & 1976 & 4 & 4 \\
\hline 1964 & 2 & 3 & 1968 & 3 & 2 & 1972 & 4 & 1 & 1976 & 5 & 0 \\
\hline 1964 & 3 & 2 & 1968 & 4 & 3 & 1972 & 5 & 1 & 1976 & 6 & 4 \\
\hline 1964 & 4 & 2 & 1968 & 5 & 2 & 1972 & 6 & 0 & 1976 & 7 & 0 \\
\hline 1964 & 5 & 1 & 1968 & 6 & 2 & 1972 & 7 & 1 & 1976 & 8 & 0 \\
\hline 1964 & 6 & 0 & 1968 & 7 & 2 & 1972 & 8 & 0 & 1976 & 9 & 2 \\
\hline 1964 & 7 & 2 & 1968 & 8 & 1 & 1972 & 9 & 1 & 1976 & 10 & 1 \\
\hline 1964 & 8 & 0 & 1968 & 9 & 1 & 1972 & 10 & 2 & 1976 & 11 & 1 \\
\hline 1964 & 9 & 6 & 1968 & 10 & 1 & 1972 & 11 & 3 & 1976 & 12 & 0 \\
\hline 1964 & 10 & 3 & 1968 & 11 & 2 & 1972 & 12 & 1 & 1977 & 1 & 2 \\
\hline 1964 & 11 & 1 & 1968 & 12 & 0 & 1973 & 1 & 2 & 1977 & 2 & 1 \\
\hline 1964 & 12 & 3 & 1969 & 1 & 1 & 1973 & 2 & 0 & 1977 & 3 & 1 \\
\hline 1965 & 1 & 1 & 1969 & 2 & 3 & 1973 & 3 & 2 & 1977 & 4 & 0 \\
\hline
\end{tabular}

ratio among other variants. Figure 3 shows graph obtained as a result of smoothing of the 9-month series of earthquakes distribution. Some character of variation with time of relatively small earthquakes number of Javakheti Highland was revealed as a result of the analysis, and the necessity for further study was obvious.
We have applied the qualitative method for anomaly separation, namely the method for summation with variable sign (Handbook, 1990) widely used in Geophysics, to separate "useful" anomalies from disturbances. The method is quite convenient even in case when the amplitude of disturbances equals or exceeds the amplitude of "useful" anomalies. 
Table 2. continued

\begin{tabular}{|c|c|c|c|c|c|c|c|c|c|c|c|}
\hline year & month & quantity & year & month & quantity & year & month & quantity & year & month & quantity \\
\hline 1977 & 5 & 1 & 1981 & 7 & 0 & 1985 & 9 & 2 & 1989 & 11 & 1 \\
\hline 1977 & 6 & 2 & 1981 & 8 & 0 & 1985 & 10 & 2 & 1989 & 12 & 3 \\
\hline 1977 & 7 & 1 & 1981 & 9 & 3 & 1985 & 11 & 1 & 1990 & 1 & 1 \\
\hline 1977 & 8 & 0 & 1981 & 10 & 1 & 1985 & 12 & 1 & 1990 & 2 & 0 \\
\hline 1977 & 9 & 3 & 1981 & 11 & 2 & 1986 & 1 & 1 & 1990 & 3 & 1 \\
\hline 1977 & 10 & 2 & 1981 & 12 & 0 & 1986 & 2 & 2 & 1990 & 4 & 1 \\
\hline 1977 & 11 & 0 & 1982 & 1 & 1 & 1986 & 3 & 3 & 1990 & 5 & 1 \\
\hline 1977 & 12 & 2 & 1982 & 2 & 3 & 1986 & 4 & 0 & 1990 & 6 & 1 \\
\hline 1978 & 1 & 9 & 1982 & 3 & 3 & 1986 & 5 & 7 & 1990 & 7 & 1 \\
\hline 1978 & 2 & 2 & 1982 & 4 & 1 & 1986 & 6 & 3 & 1990 & 8 & 1 \\
\hline 1978 & 1 & 9 & 1982 & 3 & 3 & 1986 & 5 & 7 & 1990 & 7 & 1 \\
\hline 1978 & 3 & 4 & 1982 & 5 & 7 & 1986 & 7 & 1 & 1990 & 9 & 0 \\
\hline 1978 & 4 & 2 & 1982 & 6 & 0 & 1986 & 8 & 2 & 1990 & 10 & 0 \\
\hline 1978 & 5 & 4 & 1982 & 7 & 2 & 1986 & 9 & 2 & 1990 & 11 & 0 \\
\hline 1978 & 6 & 6 & 1982 & 8 & 3 & 1986 & 10 & 0 & 1990 & 12 & 5 \\
\hline 1978 & 7 & 1 & 1982 & 9 & 2 & 1986 & 11 & 0 & 1991 & 1 & 0 \\
\hline 1978 & 8 & 4 & 1982 & 10 & 2 & 1986 & 12 & 2 & 1991 & 2 & 1 \\
\hline 1978 & 9 & 1 & 1982 & 11 & 2 & 1987 & 1 & 1 & 1991 & 3 & 1 \\
\hline 1978 & 10 & 2 & 1982 & 12 & 2 & 1987 & 2 & 1 & 1991 & 4 & 2 \\
\hline 1978 & 11 & 2 & 1983 & 1 & 2 & 1987 & 3 & 1 & 1991 & 5 & 2 \\
\hline 1978 & 12 & 0 & 1983 & 2 & 4 & 1987 & 4 & 3 & 1991 & 6 & 2 \\
\hline 1979 & 1 & 2 & 1983 & 3 & 0 & 1987 & 5 & 3 & 1991 & 7 & 2 \\
\hline 1979 & 2 & 2 & 1983 & 4 & 3 & 1987 & 6 & 0 & 1991 & 8 & 5 \\
\hline 1979 & 3 & 0 & 1983 & 5 & 1 & 1987 & 7 & 3 & 1991 & 9 & 0 \\
\hline 1979 & 4 & 0 & 1983 & 6 & 2 & 1987 & 8 & 2 & 1991 & 10 & 3 \\
\hline 1979 & 5 & 1 & 1983 & 7 & 2 & 1987 & 9 & 2 & 1991 & 11 & 0 \\
\hline 1979 & 6 & 0 & 1983 & 8 & 0 & 1987 & 10 & 1 & 1991 & 12 & 4 \\
\hline 1979 & 7 & 0 & 1983 & 9 & 3 & 1987 & 11 & 2 & 1992 & 1 & 2 \\
\hline 1979 & 8 & 1 & 1983 & 10 & 2 & 1987 & 12 & 1 & 1992 & 2 & 2 \\
\hline 1979 & 9 & 0 & 1983 & 11 & 2 & 1988 & 1 & 1 & 1992 & 3 & 1 \\
\hline 1979 & 10 & 4 & 1983 & 12 & 3 & 1988 & 2 & 1 & 1992 & 4 & 0 \\
\hline 1979 & 11 & 5 & 1984 & 1 & 3 & 1988 & 3 & 3 & 1992 & 5 & 2 \\
\hline 1979 & 12 & 4 & 1984 & 2 & 1 & 1988 & 4 & 3 & 1992 & 6 & 0 \\
\hline 1980 & 1 & 1 & 1984 & 3 & 2 & 1988 & 5 & 1 & 1992 & 7 & 1 \\
\hline 1980 & 2 & 1 & 1984 & 4 & 0 & 1988 & 6 & 3 & 1992 & 8 & 2 \\
\hline 1980 & 3 & 2 & 1984 & 5 & 0 & 1988 & 7 & 0 & 1992 & 9 & 3 \\
\hline 1980 & 4 & 0 & 1984 & 6 & 2 & 1988 & 8 & 2 & 1992 & 10 & 3 \\
\hline 1980 & 5 & 5 & 1984 & 7 & 0 & 1988 & 9 & 1 & 1992 & 11 & 2 \\
\hline 1980 & 6 & 1 & 1984 & 4 & 2 & 1988 & 10 & 0 & 1992 & 12 & 0 \\
\hline 1980 & 7 & 0 & 1984 & 9 & 1 & 1988 & 11 & 1 & 1993 & 1 & 2 \\
\hline 1980 & 8 & 1 & 1984 & 10 & 0 & 1988 & 12 & 6 & 1993 & 2 & 1 \\
\hline 1980 & 9 & 0 & 1984 & 11 & 1 & 1989 & 1 & 4 & 1993 & 3 & 2 \\
\hline 1980 & 10 & 1 & 1984 & 12 & 2 & 1989 & 2 & 3 & 1993 & 4 & 2 \\
\hline 1980 & 11 & 4 & 1985 & 1 & 3 & 1989 & 3 & 2 & 1993 & 5 & 4 \\
\hline 1980 & 12 & 4 & 1985 & 2 & 2 & 1989 & 4 & 2 & 1993 & 6 & 1 \\
\hline 1981 & 1 & 2 & 1985 & 3 & 1 & 1989 & 5 & 2 & 1993 & 7 & 0 \\
\hline 1981 & 2 & 0 & 1985 & 4 & 1 & 1989 & 6 & 7 & 1993 & 8 & 0 \\
\hline 1981 & 3 & 0 & 1985 & 5 & 1 & 1989 & 7 & 2 & 1993 & 9 & 1 \\
\hline 1981 & 4 & 2 & 1985 & 6 & 0 & 1989 & 8 & 1 & 1993 & 10 & 2 \\
\hline 1981 & 5 & 1 & 1985 & 7 & 3 & 1989 & 9 & 1 & 1993 & 11 & 0 \\
\hline 1981 & 6 & 0 & 1985 & 8 & 1 & 1989 & 10 & 3 & 1993 & 12 & 0 \\
\hline
\end{tabular}

Condition for application of the method is availability of an anomalous curve, which cuts off approximately equal areas from the axis of abscissas. We computed average value of those data, according to which Fig. 3 was drawn. This value equals 15.72. Drawing of the "zero line" across the average value made possible to apply the above-mentioned method for summation with variable sign (Naturally, the number of earthquakes was subdivided into "positive" and "negative" 

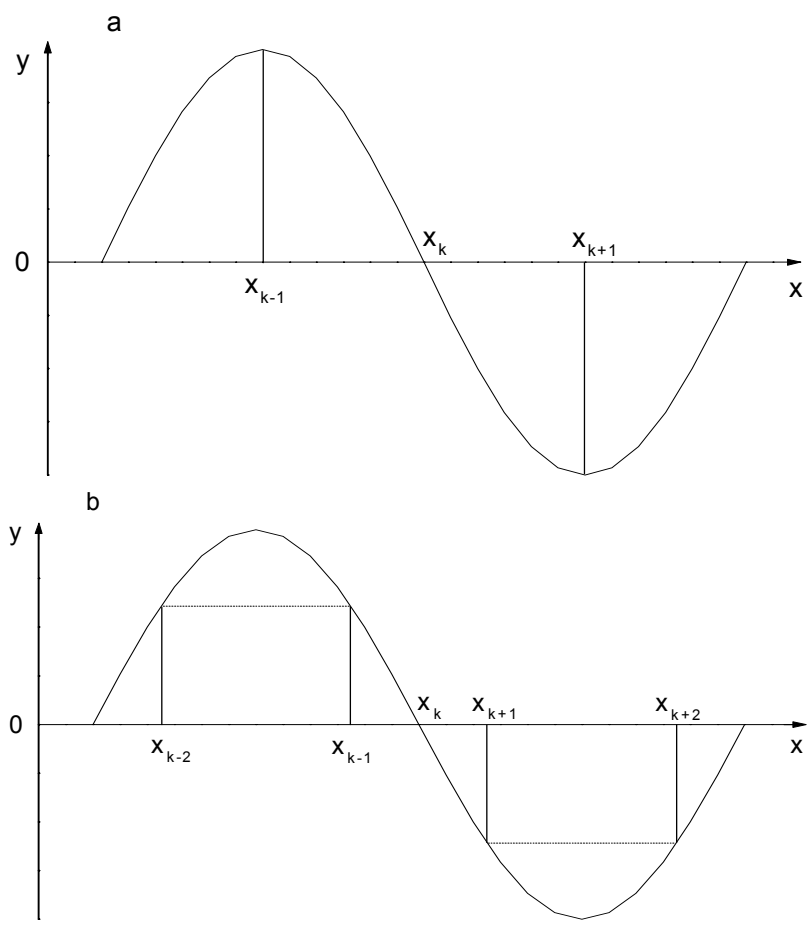

Fig. 4. Ilustration of the method of summation with variable sign.

values as a result of drawing the "zero line". The "negative" values imply decrease in the number of earthquakes).

The method of summation with variable sign is based on the amplitude doubling of the maximum anomalous signal in case of dissecting minimum value (with own sign) from the maximum one.

Difference between the ordinates of $x_{k-1}$ and $x_{k+1}$ points (Fig. 4a) is denoted by $y^{\prime}\left(x_{k}\right)$, and attributed to $x_{k}$ point:

$y^{\prime}\left(x_{k}\right)=y\left(x_{k}-1\right)-y\left(x_{k}+1\right)$.

If while transforming the anomaly we use four (or more) ordinates of the anomalous curve instead of two, as shown in Fig. 4b, we will have:

$$
y\left(x_{k}\right)=y\left(x_{k-2}\right)+y\left(x_{k-1}\right)-y\left(x_{k+1}\right)-y\left(x_{k+2}\right) .
$$

Consequently, the above method transforms each idealized anomaly with the "variable sign" into the anomaly with corresponding sign and with twofold, fourfold (multifold) amplitude.

Ratio of the amplitude of the desired signal $y_{0}$ to the square root of the amplitude's dispersion of the disturbance $\sigma_{0}$ significantly increases in case of the above transformation, and the applied operator "works" as a filter which amplifies the desired signal.

Figure 5 shows complicated anomalous pattern obtained from Fig. 3 by means of the method of summation with variable sign (with 16 ordinates). Analysis of the obtained curve, based on the gradual approximation, makes possible to delineate the certain zone with margins from +53.1 to -51 . . The "useful" anomalies observed beyond the zone, give evidence

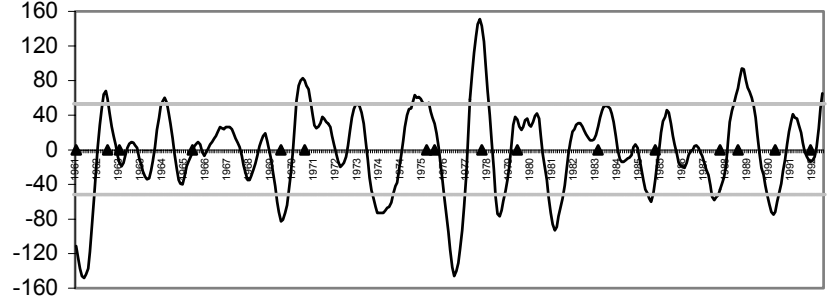

Fig. 5. Result of summation with variable sign of relatively small earthquakes.

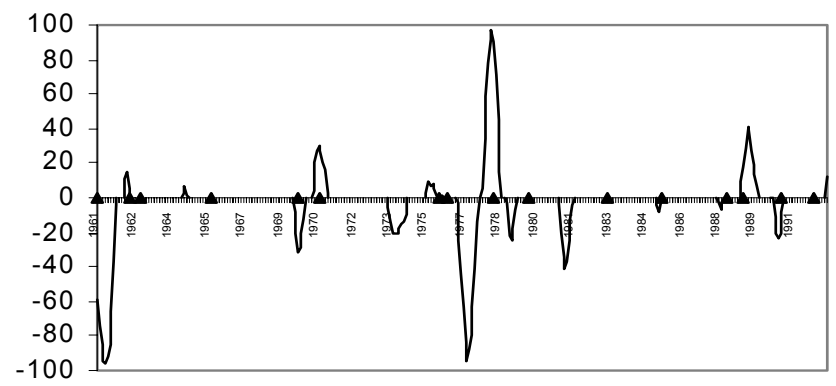

Fig. 6. "Reduced" graphs of anomalous.

of their attribution to large earthquakes. Figure 6 represents the so called "reduced" graph which was obtained after taking into consideration margins of the zone. The pattern reflects anomalous increase in the number of relatively small earthquakes occurred in Javakheti Highland as a precursor of each large earthquake

As we did not take into consideration earthquakes of Javakheti Highland occurred before 1961 due to inferior results of computations that can be attributed to peculiarities of the method (lack of the read off points is implied), we have neglected large earthquakes only of 1961 and 1992 (just 2 events). For all the other 14 large earthquakes of the Caucasus the regularity is observed.

Figure 6 illustrates good quantitative coincidence of anomalous picks with the number of earthquakes with one exception: the large earthquake occurred in 1978 was preceded by two anomalous picks.

Table 3 was compiled as a result of the critical analysis of Fig. 6. The table helped us to establish the minimal size of the anomaly the numeral value increase of which shows us the possibilities of an occurrence of large earthquake. The minimal size of the anomaly was found to equal $|6.2|$. Maximum and minimum time lags from the starting point of the anomaly till earthquake occurrence are 31 months and 1 month, respectively.

\section{Conclusion}

We should state that all the large earthquakes $(M \geq 6.0)$ which occurred in the Caucasus within the period from 1961 till 1992 were preceded by anomalous change in the number of relatively small earthquakes $(2.5 \leq M<6.0)$ of Javakheti 
Table 3. Estimate of anomalous

\begin{tabular}{|c|c|c|c|c|c|}
\hline $\begin{array}{l}\text { Occurrence time } \\
\text { of the earthquake }\end{array}$ & Magnitude & $\begin{array}{c}\text { Distance from } \\
\text { Javakheti Highland } \\
\qquad(\mathrm{km})\end{array}$ & $\begin{array}{c}\text { The maximum value } \\
\text { of anomaly }\end{array}$ & $\begin{array}{c}\text { The minimum value } \\
\text { of anomaly }\end{array}$ & $\begin{array}{c}\text { Time lag between the } \\
\text { starting point of } \\
\text { the anomaly and earthquake } \\
\text { occurrence (month) }\end{array}$ \\
\hline 18 Sept. 1961 & 6.6 & 538.9 & & & \\
\hline 27 Jan. 1963 & 6.2 & 505.9 & 14.9 & -96 & 16 \\
\hline 16 July 1963 & 6.4 & 273.9 & 14.9 & -96 & 22 \\
\hline 19 Aug. 1966 & 6.8 & 304.6 & 6.9 & & 15 \\
\hline 14 May 1970 & 6.6 & 330.1 & & -31 & 2 \\
\hline 22 May 1971 & 6.8 & 390.2 & 29.9 & & 4 \\
\hline 28 July 1976 & 6.2 & 255.3 & 9 & -21 & 27 \\
\hline 24 Nov. 1976 & 7.0 & 245.2 & 9 & -21 & 31 \\
\hline 4 Nov. 1978 & 6.0 & 608.7 & 97.9 & -94 & 19 \\
\hline 4 May 1980 & 6.2 & 598.1 & & -25 & 11 \\
\hline 30 Oct. 1983 & 6.8 & 236.4 & & -41 & 25 \\
\hline 6 March 1986 & 6.1 & 674.3 & & -8.2 & 3 \\
\hline 7 Dec. 1988 & 6.9 & 55.7 & & -6.2 & 4 \\
\hline 16 Sept. 1989 & 6.3 & 664.7 & 40.9 & & 1 \\
\hline 29 April 1991 & 6.9 & 121.6 & & -23 & 4 \\
\hline 23 Oct. 1992 & 6.3 & 164.9 & & & \\
\hline
\end{tabular}

Highland. We consider this peculiarity as the marked precursor.

Getting results show that special seismoactivity of Javakheti Highland reflects the global process of preparing of large earthquakes throughout the whole Caucasus region.

\section{References}

Borisov, N., Chmyrev, V., and Rybachek, S.: A new ionospheric mechanism of electromagnetic ELF precursors to earthquakes, J. Atmos. Solar-Terr. Phys., 63, 1, 3-10, 1989.

Chadwick, W. W. Jr., Archuleta, R. J., and Swanson, D. A.: The mechanics of ground deformation precursory to dome-building extrusions at Mount St. Helens 1981-1982, J. Geophys. Res., 93, 4351-4366, 1988.

Dea, J. Y., Richman, C. I., and Boerner, W.-M.: Observations of seismo-electromagnetic earthquake precursor radiation signatures along Southern California fault zones - Evidence of longdistance precursor ultra-low frequency signals observed before a moderate Southern California earthquake episode, Canadian J. Phys., 69, 1138-1145, 1991.

Duff, R. E. and Peterson, F. I.: Shock precursor observations, Precursor transition in dynamical systems undergoing period doubling, J. App. Phys., 51, 7, 3957-3959, 1980.

Gotsadze, O. and Pilishvili, T.: Regime of realization of seismic energy on Caucasus and in the epicenter zones of some large earthquakes. Identification of geophysical precursors of earthquakes in the Caucasus, Publishing House "Metsniereba", Tbilisi, 54, 15-27, 1987.

Handbook of Geophysicist, Moscow, "Nedra”, 6, 469, 1990.

Hayakawa, M., Kopytenko, Y., Smirnova, N., Troyan, V., and Peterson, T. H.: Monitoring ULF magnetic disturbances, and schemes for recognizing earthquake precursors, Phys. Chem. Earth A, 25, 3, 263-269, 2000.
Keilis-Borok, V. I., Knopoff, L., Rotvain, I. M., and Sidorenko, T. M.: Bursts of seismicity as long-term precursors of strong earthquakes, J. Geophys. Res., 85, B2, 803-812, 1980.

Kuloshvili, S., Maisuradze, G., and Tsagareli, A.: Geological and geomorphologic studying and seismotectonics of the prognostic polygons, Earthquake Prognosis, Publishing House "Donish", Dushanbe-Tbilisi, 335, 1989.

Kumar, K., Agarwal, A. K., Bhattacharjee, J. K., and Banerjee, K.: Precursor transition in dynamical systems undergoing period doubling, Physical Review, 35, 5, 2334-2336, 1987.

Papadopoulos, G. A., Drakatos, G., and Plessa, A.: Foreshock activity as a precursor of strong earthquakes in Corinthos Gulf, Central Greece, Phys. Chem. Earth A, 25, 3, 239-245, 2000.

Park, S. K., Johnston, M. J. S., Madden, T. R., Morgan, F. D., and Morrison, H. F.: Electromagnetic precursors to earthquakes in the ulf band, Rev. Geophys., 31, 2, 117-132, 1993.

Rundle, J. B., Klein, W., Turcotte, D. L., and Malamud, B. D.: Precursory Seismic Activation and Critical-point Phenomena, Pure and Applied Geophysics, 157, 2165-2182, 2000.

Shebalin, P., Girardin, N., Rotwain, I., Keilis-Borok, V., and Dubois, J.: Local overturn of active and non-active seismic zones as a precursor of large earthquakes in the Lesser Antillean Arc, Phys. Earth and Planet. Int., 97, 163-175, 1999.

Sorrells, G., Bonner, J., and Herrin, E. T.: Seismic Precursors to Space Shuttle Shock Fronts, Pure and Applied Geophysics, 159, 5, 1153-1181, 2002.

Tzanis, A., Valliantos, F., and Makropoulos, K.: Seismic and electrical precursors to the 17 January 1983, Phys. Chem. Earth A, 25, 3, 281-287, 2000.

Westaway, R.: Seasonal Seismicity of Northern California Before the Great 1906 Earthquake, Pure and Applied Geophysics, 159, $1-3,7-62,2002$. 